\title{
Analysis of Construction Project Safety Management Influence Factors Based on Clustering Algorithm
}

\author{
BuXiangyi \\ Wuhan University of Technology,Wuhan 430070,China
}

Keywords: Construction project; safety management; factor analysis; clustering algorithm; tree diagram

\begin{abstract}
In order to explore the main influencing factor of safety management of construction project proposed a based on clustering algorithm of safety management factors analysis method, and the main factors of influencing the construction safety management through the practical investigation. By a factor of 16 questionnaire as the basic data, using multivariate statistical analysis method of factor analysis method analyzes the results of the survey, six main affecting factors of construction safety and project management, and then analyzes the main factor clustering. Through the analysis of the factors of the characteristic value of the stone figure and factor analysis of the tree, by factor analysis and cluster analysis of the results summed up the impact of construction safety management of the five main areas.
\end{abstract}

\section{Introduction}

Construction safety accidents occur frequently, on the one hand, it caused a great economic loss and casualties to the country, society and people, wasting a lot of social resources, increase the enterprise cost of inaction, affecting the construction industry sustainable development, on the other hand it also affects of injured workers family of happy life, endanger the construction of a harmonious socialist society. Therefore, it is an important subject to study the safety management of the construction project, and to analyze and evaluate the safety management of the construction project. There are many factors influencing the construction safety management, if to get the main factors from the numerous influencing factors and need to combine some of the current popular data processing algorithm of factor analysis, which has important practical significance for the construction project safety management research.

\section{Overview of construction project safety management factor analysis method}

Factor analysis is used to explore the basic method of observation data by using the internal relations among numerous variables, and the basic structure of the expression factor is expressed by several hypotheses. Assuming that these variables can reflect the main information of the original numerous variables to express the. So the method of factor analysis is how to use less factor to express many variables, is a branch of statistical techniques for the analysis of originally from developmental psychology. This study uses factor analysis method to analyze the influence factors of construction safety management, and combined with the clustering algorithm to optimize the factor analysis, the specific process as shown in figure 1. 


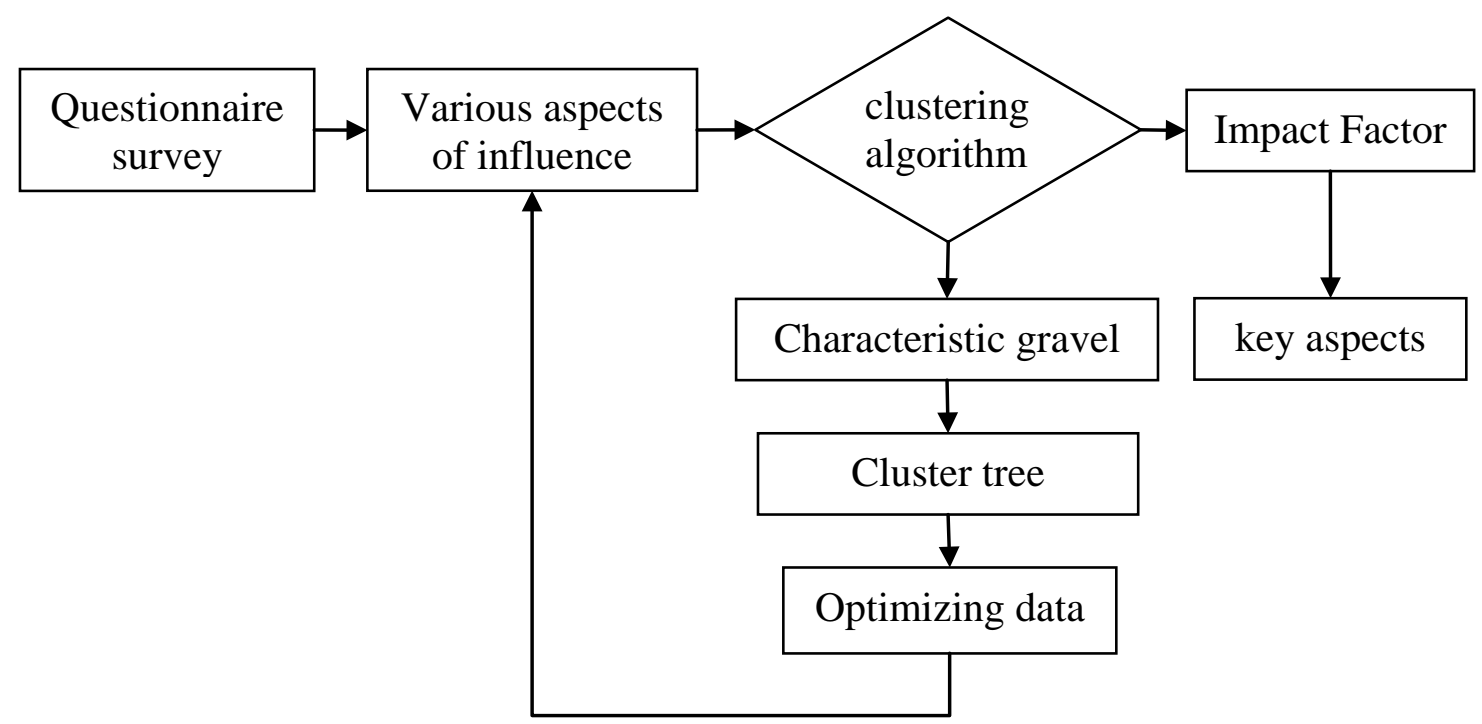

Fig. 1 factor analysis clustering algorithm optimization block diagram

As shown in Figure 1, the questionnaire data first by initializing the screening, the screening of the data can be the main influence factor was calculated by SPSS software, and then use the clustering algorithm characteristic graphs of the gravel impact factor calculation, the shadow effect can be obtained by further calculation of the cluster dendrogram.

\section{Security management factor analysis clustering algorithm}

Suppose the data sample of the construction project safety management document is $b_{k}=\left(b_{k 1}, b_{k 2}, \ldots b_{k n}\right)$, the distance between $b_{k}, b_{l}$ data can be defined as,

$$
d\left(b_{k}, b_{l}\right)=\sqrt{\sum_{z=1}^{c}\left(b_{k z}-b_{l z}\right)}, k, l=1,2, \ldots n
$$

The density of the data sample point bk can be expressed as the following formula (2).

$$
M_{k}=\sum_{l=1}^{n} \frac{d\left(b_{k}, b_{l}\right)}{\sum_{k=1}^{n} d\left(b_{l}, b_{e}\right)}, k=1,2, \ldots n
$$

Therefore, the next best cluster center can be selected, the first to make the density around the sample density is relatively dense, the density can be defined as the following formula (3).

$$
M p_{k}=\exp \left(-\frac{M_{k}}{\sum_{i=1}^{g} d\left(B_{j}, s_{i}\right)}\right), j=1,2, \ldots . n, j \neq i
$$

Analysis of construction safety management factors through the input of shadow classification information search $\mathrm{P}$ source and the influence factors on the database system of $\mathrm{B}$ in without a priori knowledge of, the output data of the clustering algorithm s to estimate the Q and $\mathrm{B}$, its structure is as the following Fig.2. 


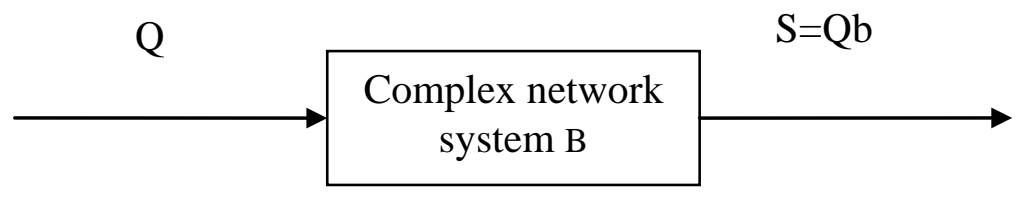

Fig.2 The clustering algorithm structure

Assuming that $\mathrm{Q}$ is a $\mathrm{m}$ dimensional vector, the expression of $\mathrm{Q}$ is $\mathrm{Q}=[\mathrm{Q} 1, \mathrm{Q} 2, \ldots \mathrm{Qm}]^{\mathrm{T}}$, assuming that there is a relatively independent relationship between the various factors, such as the formula (4)

$$
Q(P)=\prod_{j=1}^{n} Q\left(P_{j}\right)
$$

Safety management effect of shadow search through the source P through the B clustering algorithm as a linear combination of the n-dimensional visualization vector $S, S=[S 1, S 2, \ldots S n]^{T}$, written in the form of independent components as follows

$$
S_{j}=\sum_{i=1}^{n} s_{j i} p_{i}, j=1,2, \ldots, m
$$

Written in vector form as

$S=P b$

For complex multi factor image search can combined with network nodes to implement, make the existence of contact between the different factors of keywords, and according to the characteristics of factor, each influence factor of clustering, the main influencing factor of safety management, the steps:

Step 1: enter the survey data set;

Step 2: to classify the data, the main factors are calculated by SPSS software, and then the factors are classified;

Step 3: the influence factor of the weight of the factor, the weight can be defined as the formula (7).

$$
w_{t r}=\log \left(1+\frac{\operatorname{Tr} e\left(e_{i}, e_{r}\right)}{\operatorname{Tre}\left(e_{i}\right)+\operatorname{Tr} e\left(e_{r}\right)-\operatorname{Tr} e\left(e_{i}, e_{r}\right)}\right)
$$

In the formula (7), $\operatorname{Tr} e\left(e_{i}, e_{i}\right)$ is characteristics of factor $e_{i}, e_{i}$ in the span of less than 2 the characteristic factors of co-exist frequency, $\operatorname{Tr} e\left(e_{i}\right), \operatorname{Tr} e\left(e_{j}\right)$ are the frequency characteristic factor classification, $\operatorname{Tr} e\left(e_{i}, e_{i}\right)$ is the frequency factor, and if the $\operatorname{Tr} e\left(e_{i}\right)$ value is greater, the frequency of factor is higher.

Step 4: the establishment of the impact factor classification search data, the factor in accordance with the characteristics of the gravel value of the merger and classification;

Step 5: calculate the weight of each influence factor, and the weight of the normalization process, get the weight of the evaluation function.

$$
W=\alpha_{1} W_{1}+\alpha_{2} W_{2}+\alpha_{3} W_{3}
$$

In the formula (8), $\alpha_{i}, i=1,2,3$ Is adjustable parameters, representing the weight coefficient, and $\alpha_{1}+\alpha_{2}+\alpha_{3}=1$ 。

\section{Analysis on Influence Factors of safety management in Construction project}

The study in the form of questionnaire survey on construction safety factors were analyzed, in order to simplify the research content, the main consideration of the 16 factors to make a questionnaire, the specific content of the 16 factors such as table 1 shows. 
Table 1 Questionnaire of influence factors of construction safety management

\begin{tabular}{|c|c|c|c|c|c|c|}
\hline \multirow[b]{2}{*}{$\begin{array}{l}\text { Serial } \\
\text { number }\end{array}$} & \multirow[b]{2}{*}{$\begin{array}{l}\text { Variable } \\
\text { number }\end{array}$} & \multirow[b]{2}{*}{ Variable description } & \multicolumn{4}{|c|}{ Correlation degree } \\
\hline & & & $\begin{array}{l}\text { Very not } \\
\text { related }\end{array}$ & $\begin{array}{l}\text { Not } \\
\text { related }\end{array}$ & related & $\begin{array}{c}\text { Very } \\
\text { related }\end{array}$ \\
\hline 1 & $\mathrm{X} 1$ & Less construction site & & & & \\
\hline 2 & $\mathrm{X} 2$ & Tense construction period & & & & \\
\hline 3 & X3 & difficult construction & & & & \\
\hline 4 & $\mathrm{X} 4$ & $\begin{array}{l}\text { construction quality } \\
\text { requirements are high }\end{array}$ & & & & \\
\hline 5 & X5 & $\begin{array}{l}\text { Security special fund } \\
\text { shortage }\end{array}$ & & & & \\
\hline 6 & X6 & Design file deletion & & & & \\
\hline 7 & $\mathrm{X7}$ & $\begin{array}{l}\text { Ignore security } \\
\text { management }\end{array}$ & & & & \\
\hline 8 & $\mathrm{X} 8$ & $\begin{array}{l}\text { Design change frequency } \\
\text { is high }\end{array}$ & & & & \\
\hline 9 & X9 & The quality ability is low & & & & \\
\hline 10 & $\mathrm{X} 10$ & $\begin{array}{l}\text { Supervision engineer } \\
\text { certificate }\end{array}$ & & & & \\
\hline 11 & $\mathrm{X} 11$ & $\begin{array}{l}\text { Ignore Supervision } \\
\text { Engineer }\end{array}$ & & & & \\
\hline 12 & $\mathrm{X} 12$ & Enterprise security level & & & & \\
\hline 13 & $\mathrm{X} 13$ & $\begin{array}{l}\text { Enterprise security } \\
\text { supervision system }\end{array}$ & & & & \\
\hline 14 & X14 & $\begin{array}{l}\text { Safety production } \\
\text { responsibility }\end{array}$ & & & & \\
\hline 15 & X15 & $\begin{array}{l}\text { Safety education and } \\
\text { training }\end{array}$ & & & & \\
\hline 16 & $\mathrm{X} 16$ & Safety accident treatment & & & & \\
\hline
\end{tabular}

In order to improve the accuracy of the calculation, on the recovery of the questionnaire first preliminary screening, screening basis for the validity and integrity of the questionnaire, the primary qualified for the software using SPSS15.0 for reliability test and factor analysis, the last remaining six factors, and the factor of clustering analysis.

Table 2 reliability test results

\begin{tabular}{|l|l|}
\hline \multicolumn{2}{|c|}{ Reliability Coefficients } \\
\hline N of Cases $=538.8$ & N of Items $=33$ \\
\hline \multicolumn{2}{|c|}{ Alpha $=0.9188$} \\
\hline
\end{tabular}

Table 2 is the test results of using SPSS software to test the reliability, it is generally believed that if the krona strike Korhal -O son test reached a value of 0.7 , that the result of the questionnaire is credible, from table 2 results can be seen, the statistics of the questionnaire is reliable. 


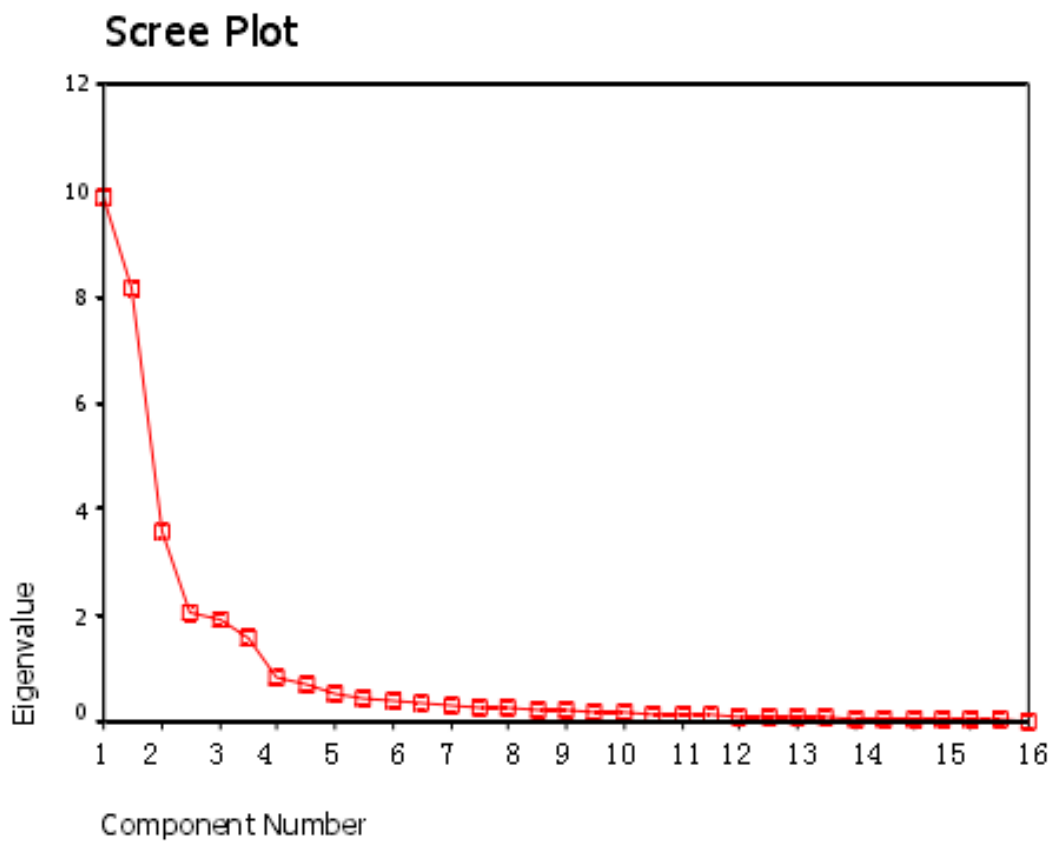

Fig.3 Gravel map of each factor characteristic values

Figure 3 shows the gravel characteristic figure of each component obtained by analysis with SPSS software, it can be seen from the chart that, the differences of feature value are big that between factor 1 and 2, factor 2 and 3, factor 3 and 4, factor 4 and 5, factor 5 and 6 of the, and factor 7 and 8, factor 8 and $9, \ldots$ And differences of feature value between factor 15 and factor 16 are relatively small, so it can be concluded that, in front of the six factors can contain most of the information, and the seven factors have obvious inflection point, thus the extracted six factors are more appropriate.

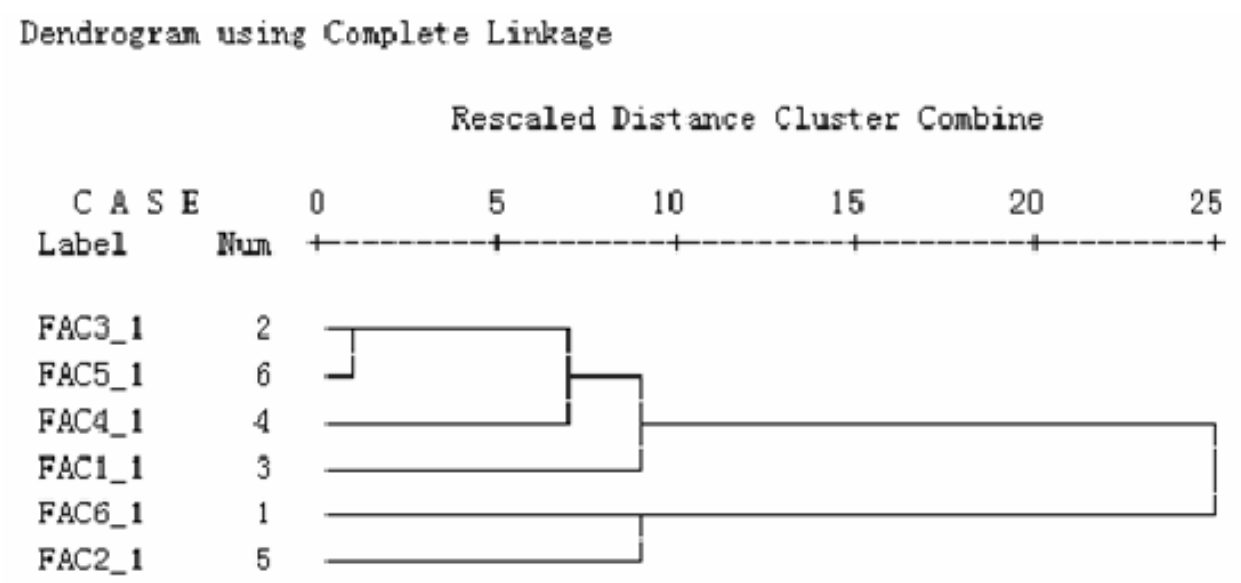

Fig.4 factor analysis cluster tree diagram

We can be seen that the six factors can be divided into five categories by the factor analysis of the tree diagram, including Fac3 and Fac5 can be classified into one category, and the other factors are classified as a class. Because of the high correlation between the two factors of Fac3 Fac5 can will they are unified as factor owners will eventually belong to me five main aspects of construction project safety factors, including owners and enterprises to monitor the safety and education, construction of the security management ability, the construction unit of the qualification and major hazard project control etc.. 


\section{Summary and discussion}

This research mainly uses the factor of safety analysis of clustering algorithm on the construction affect the safety factors are analyzed, and by a factor of 16 questionnaire as the basic data using SPSS software for data processing, the characteristics of each factor values scree plot and factor analysis cluster tree diagram. From the results of factor analysis and cluster analysis see, five main factors influencing the construction safety management, including owners, enterprise safety supervision and education, the construction safety management ability, the construction unit qualification and major hazard to control. To realize safe production of construction industry, we suggest proceed mainly from the five aspects mentioned above, make detailed safety management system, strengthen safety supervision, improve the comprehensive quality of the safety supervision personnel, regular training for staff, can effectively improve the construction project security efforts.

\section{Reference}

[1] He Yao, Wang Wenqing, Xue fei. Research on massive data mining based on cloud computing [J]. Computer technology and development, 2013, 23 (2): 69-72

[2] Ding Yan, Yang Qingping, Qian Yuming. Research on the architecture and key technologies of data mining platform based on cloud computing [J]. ZTE technology, 2013,19 (1): 53-60

[3] Li Kai, Chang Zheng. Design and implementation of parallel data mining system based on cloud computing [J]. micro computer information, 2011, 27 (6): 121-123

[4] Sun Guanglu, Qi Haoliang. The spam filtering based on online scheduling logic regression [J]. Journal of Tsinghua University, 2013, 53 (5):734-740

[5] Liu Botao. Research on data mining algorithms based on rough sets [J]. China western science and technology, 2011, 10 (14): 11-12

[6] Hu Jiance, Wu Guoping. An improved genetic BP neural network data mining algorithm and application of [J]. Microcomputer and application, 2011, 2: 030

[7] Chu Bing, Wu Chen, Yang Xibei. Data mining algorithm based on RBF neural network and rough set [J]. Computer technology and development, 2013,23 (7): 87-91

[8] Zhang Xin, Huang Yiping, Fang Dongping. Quantitative research on the influence of the owner on the safety performance of the project. Journal of civil engineering.2006,6 (39): 123-127

[9] Pan Chengshi, Zhang Shilian. The significance of safety management to the construction project management. Building economy, 2003, 24 (12): 43-44

[10] Fang Dongping, Wu Shenghou, Bi Shutao etc.. Scaffold accidents caused by cause analysis and Countermeasures of safety management. Journal of Civil Engineering (Construction project and Management Sciences, 2002,8. 25-30

[11] Zhao Tingsheng, Lu Xuewei, Fang Dongping. Investigation and analysis of the incentive factors of construction accidents. Construction technology.2003.12 (33): 56-60

[12] Zhao Tingsheng, Fang Dongping, Wang Zehui. Construction quality and safety control of concrete construction. Construction technology.2005,04 (35): 24-26

[13] Zhang Li, He Xueqiu. Application of safety rheology theory in mine accidents. Journal of Safety Science in China.2001,11 (1): 6-11 
[14] Zhang Xin, Mao Baohua. Analysis of traffic accident process based on the theory of safety rheology. Journal of safety science and technology of China.2004, 14 (1): 18-22. 